\title{
Cultural evolution and music
}

\author{
Mason Youngblood ${ }^{1, a}$, Yuto Ozaki², and Patrick E. Savage ${ }^{2, b}$ \\ ${ }^{1}$ Minds and Traditions Group, Max Planck Institute for the Science of Human History, Germany \\ ${ }^{2}$ Faculty of Environment and Information Studies, Keio University, Japan \\ 2youngblood@shh.mpg.de \\ bsavage@sfc.keio.ac.jp \\ For submission to the Oxford Handbook of Cultural Evolution, edited by J. Tehrani, J. R. Kendal, and R. L. Kendal.
}

\begin{abstract}
The universality and diversity of music in human societies make it an important research model for understanding how cultural features change over time and space. In this chapter, we review research on the cultural evolution of music, broken down into three major approaches: 1) corpus-based approaches that use large datasets to infer evolutionary patterns, 2) experimental approaches that explore cultural transmission and transformation, and 3) research on "music-like" behaviors in non-human species, such as bird and whale song, that highlights shared mechanisms and future directions. Finally, we discuss applications of this research to issues like musical endangerment, copyright enforcement, and algorithmic inequality. Given the diversity of musical datasets that have yet to be fully leveraged, we think that music has the potential to become a powerful research model for cultural evolution.
\end{abstract}

Keywords: cultural evolution, music, bird song, whale song, copyright, algorithms

\section{Introduction}

Music, like language, is found in all known human societies, yet varies greatly within and between societies (Brown, 1991; Brown and Jordania, 2013; Mehr et al., 2019; Nettl, 2015; Patel, 2008; Savage et al., 2015). While language research has been fundamental in establishing the field of cultural evolution (Bailes and Cuskley, this volume), there has been comparatively little research on the cultural evolution of music despite many parallels between music and language (Deutsch et al., 2011; Engelhardt and Bretèque, 2017; Feld and Fox, 1994; Fitch, 2006; Patel, 2008). We propose that music is an important domain that deserves more attention from cultural evolution researchers.

Evolutionary approaches have been present in musicology since the 19th century, but fell out of favor during the mid-20th century. A full review of the reasons for this are beyond the scope of this chapter, but a crucial factor was the mistaken reliance of early comparative musicologists on colonialist/racist models of unilinear evolution from "primitive" hunter-gatherer societies with simple folk music to Western societies with complex art music (for review, see Nettl and Bohlman, 1991; Nettl, 2006; Rahaim, 2006; Mundy, 2014; Savage, 2019). Previously, Savage (2019) reviewed this history and attempted to correct this misunderstanding and justify the value of modern cultural evolutionary methods to (ethno)musicologists and others in music studies who may be skeptical about the concept of "cultural evolution".

In this chapter, we focus on a different audience: rather than trying to convince skeptical musicologists about the value of cultural evolutionary theory and methods, we aim to convince cultural evolutionary researchers about the value of musicological data and methods that have been under-researched due to this historical aversion to cultural evolution. To do so, we review recent and historical research on the cultural evolution of music, focusing on three major approaches most likely to interest other cultural evolutionary researchers: 1) corpus-based approaches that apply statistical methods to large datasets to infer evolutionary patterns, 2) experimental approaches that explore how factors such as cognitive biases influence cultural transmission and transformation, and 3) research on "music-like" behaviors in non-human animals that highlights shared mechanisms and potential directions for future work on human music. Finally, we discuss applications of research on the cultural evolution of music to current issues such as copyright enforcement and algorithmic inequality.

Before we delve into research on the cultural evolution of music, we would first like to briefly review the topic of biological evolution of "musicality" (the capacity to produce and perceive music; Honing, 2018). Biological evolution is not 
the focus of this chapter but is closely connected, particularly since some propose that musicality arose through a process of gene-culture coevolution (Patel, 2018; Savage et al., 2021a). Recent special issues of Philosophical Transactions of the Royal Society $B$ and Behavioral and Brain Sciences on the biological evolution of musicality include dozens of contributions from over 100 researchers (see Honing et al., 2015; Honing, 2018; Mehr et al., 2021; Savage et al., 2021a and associated articles and commentaries ${ }^{1}$ ). Historical debate has focused on whether musicality is an evolutionarily "useless" byproduct of other cognitive adaptations such as language (Pinker, 1997) or a biological adaptation for specific functions such as wooing mates (Darwin, 1871; Miller, 2000), rearing babies (Dissenayake, 2000), or bonding groups (Roederer, 1984; Brown, 2000).

Recent debate has moved toward more general overarching super-functions such as social bonding (e.g. of groups, mating partners, parent-child; Savage et al., 2021a) or signaling (e.g. of group strength or parental attention; Mehr et al., 2021), which may not be mutually exclusive (Savage et al., 2021b). Crucially, the importance of incorporating the cultural evolution of music has emerged as a major theme (Mehr et al., 2021; Savage et al., 2021a; Scott-Phillips et al., 2021), which we focus on in the rest of this chapter.

Whatever its origins, music is inarguably central to human culture, and as a result there is an incredible depth and variety of data available for use in research. For example, from a single group of performers one could theoretically collect data on population structure, the content of the music being performed, the process of transmission between individuals, and the instruments, social contexts, and ecological factors that shape the entire process (see Figure 1). In the following sections, we review work exploring these different types of data and different methodologies used to approach them.

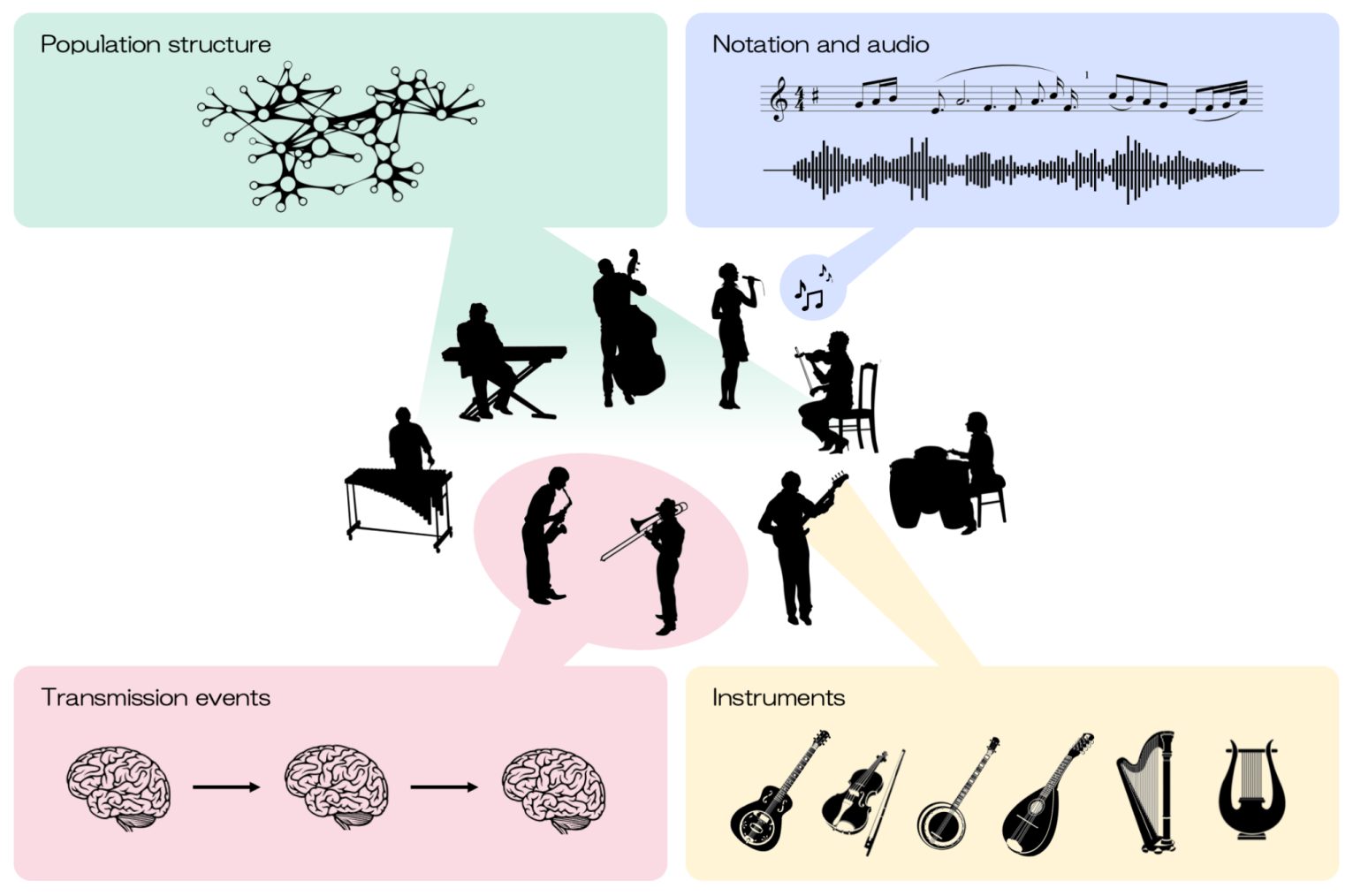

Figure 1. Four common forms of data used in studies of the cultural evolution of music. Green (top left): population structure and the social/cultural context in which music is produced (most common in corpus-based and non-human studies). Blue (top right): notation and/or recorded audio of compositions and performances (common among all approaches). Pink (bottom left): variation in cognitive representations of melodies, rhythms, and other cultural variants across transmission events (most common in experimental studies). Yellow (bottom right): instruments and contextual factors (e.g. ritual, dance) that shape and constrain the kinds of music that can evolve (somewhat common among all approaches).

\footnotetext{
${ }^{1}$ Note that there is no consensus on how to define "music" in a cross-culturally valid way. See the special issues mentioned for detailed discussion of definitional issues).
} 


\section{Corpus-Based Approaches}

\subsection{Traditional and Folk Music}

Research on the cultural evolution of traditional and folk music was pioneered by early comparative musicologists (see reviews by Nettl and Bohlman, 1991; Savage and Brown, 2013) and reached a temporary peak in the middle of the 20th century in the work of Alan Lomax's Cantometrics Project. Lomax compared thousands of songs from hundreds of societies around the world using a standardized song classification scheme, providing the first large-scale data for cross-cultural musical comparisons and arguing that musical style reflected both cultural history and social structure (Lomax, 1968; Lomax, 1980; Lomax and Berkowitz, 1972; Savage, 2018; Wood et al., 2021). Although the Cantometrics Project's methods and findings have been subject to debate (e.g. sampling, classification reliability, statistical treatment of autocorrelation; see Savage, 2018), Lomax's interest in using comparative approaches to understand the underlying evolutionary processes that explain musical diversity resonates well with contemporary cultural evolution research (Mesoudi, 2011).

While Cantometrics focused on macroevolution of broad cross-cultural stylistic differences, other researchers have examined microevolution of variation at smaller scales. For example, folk song melodies evolve through a process of descent with modification that leads to variation in time and space (International Folk Music Council, 1955; Bronson, 1969; Savage, 2019). By using sequence alignment methods adapted from genetics, researchers can identify tune families (Savage and Atkinson, 2015), or clusters of similar melodies sharing common ancestry, and infer the processes that drive their evolution over time. For example, some types of melodic modifications may be more likely than others because they are easier to sing or less noticeable to listeners. In a recent study of over 10,000 Japanese and English folk melodies, Savage et al. (2022) found that modifications that have a smaller impact on the melody are more likely to change and have those changes persist in the population. This finding was consistent despite striking differences in the scales used in Japanese and English folk music. The generality of this sequence alignment method has reopened discussion of the controversial topics of "memetics", units of cultural transmission, and analogies and differences between genetic and cultural evolution (Hoeschele and Fitch, in press; Laland and Brown, 2011).

In addition to melodies, interval structures in musical scales have been studied to detect evolutionary diversification or convergence. McBride and Tlusty (2019; 2021) recently compiled 896 scales (some theory-driven based on frequency ratios and some actually measured from audio recordings) from 55 sources spanning 39 countries to analyze cross-cultural variation in them. They discovered a strong cross-cultural tendency for scales to have either 5 or 7 notes and to include perfect fifths and octaves, supporting previous theoretical and empirical studies (Brown and Jordania, 2013; Savage et al., 2015; Kuroyanagi et al., 2019).

Data on folk melodies and scales, as well as rhythms, have also been used to test cultural evolutionary hypotheses at the population level. For example, it is often assumed that population size and cultural complexity are positively correlated, but Street et al. (2021) recently found a non-linear (inverted U-shaped) relationship between population size and musical complexity among Irish folk melodies. Similarly, Le Bomin et al. (2016) applied phylogenetic analysis to melody and scale data from Gabonese folk songs to conclude that vertical transmission may play a greater role in musical diversity than previously thought. Other researchers have used phylogenetic analysis to investigate the relationships between, and reconstruct the ancestral states of, rhythmic patterns in clave (Toussaint, 2002), flamenco (Díaz-Báñez et al., 2004), and African ternary music (Toussaint, 2003). By using this approach, Díaz-Báñez et al. (2004) not only confirmed that fandango and soleá position are central to the flamenco family, but also highlighted the fact that guajira may have had more influence on other flamenco rhythms than previously thought. Such approaches can complement traditional ethnomusicology by generating new hypotheses that may not otherwise be apparent. However, researchers should exercise caution in assuming that tune and rhythm families represent distinct lineages, as some music traditions have more complex histories due to factors such as commercial publishing and distribution (Pendlebury, 2020), hybridization of distinct lineages, or convergent evolution of similar musical structures in unrelated lineages (Trehub, 2015).

Instrument structure has also been a focus of research on traditional and folk music, as well as research on material culture more broadly. Tëmkin and Eldredge (2007) applied phylogenetic analysis to cornet and Baltic psaltery data to reconstruct the evolutionary trees of those two types of instruments. Their inference displayed a number of reticulation 
nodes in the phylogenetic tree, and highlights the issues that can arise when traditional phylogenetic methods are applied to material culture and other domains without clear ancestor-descendant relationships. Instrument structure may also provide insights about cumulative cultural evolution. For example, Nia et al. (2015) found that f-holes in violins and their ancestors have become increasingly efficient in terms of air-resonance power over time, in a manner that is consistent with a process of mutation and selection among violin makers. Geographic and historical patterns of instruments in the archaeological record can also be used to make inferences about population history and cultural extinction. Aguirre-Fernández et al. (2021) analyzed the distribution of indigenous South American instruments over time, and found that clusters of structurally similar instruments map onto established geographic and cultural (and sometimes linguistic) boundaries. They also found that a quarter of instruments in the archaeological record are absent in the ethnographic record, partly due to extinction events triggered by European contact.

One of the least studied aspects of traditional music is timbre, or the "character" of a sound. Timbre is notoriously difficult to quantify (Thoret et al., 2021) and has historically been overlooked by Western researchers (with the notable exception of Cantometrics), and yet is a fundamental component of music traditions. Nikolsky et al. (2020) argue that, since timbral details are lost in collective performances, solo music traditions like the Eurasian jaw harp may prioritize timbre as a form of self-expression. Investigating the role of timbre in traditional music may help us to better understand why solo performance, which is difficult to integrate into current hypotheses about the social origins of music (Patel and von Rueden, 2021), is so widespread in human societies.

Data on traditional and folk music has also been used to investigate the extent to which musical diversity has been shaped by population history over the course of human evolution. Among nine indigenous populations in Taiwan, musical, linguistic, and genetic diversity are all correlated with at least one of the other markers, suggesting parallel population histories (Brown et al., 2014). However, a study of 14 northeast Asian populations found significant relationships only between genetics and grammar, but not music or linguistic lexicon (Matsumae et al., 2021). A global analysis found that musical diversity was correlated with both linguistic and genetic diversity, but the correlations were relatively weaker than those between language and genes or especially between genes and geography (Passmore et al., in prep). This suggests a more complex picture in which music, language, and genes may follow somewhat divergent evolutionary pathways, while still not being completely independent.

Other researchers have combined data on traditional and folk music with ethnographic data to explore the social and behavioral drivers of music. For example, music is found in particular behavioral contexts across societies (e.g. ritual, dance, infancy), and the primary context in which a song is used is associated with certain acoustic features (Mehr et al., 2019) and reliably recognized by both adults (Mehr et al., 2018) and children (Hilton et al., 2021). Cross-cultural variation in musical styles, captured by variables like melodic interval size and level of embellishment, also appears to be robustly correlated with various measures of social complexity, such as community size and the degree of hierarchy (Lomax, 1968; Wood et al., 2021). The datasets used in both sets of studies are available online as the Natural History of Song ${ }^{2}$ and the Global Jukebox ${ }^{3}$, respectively, and we look forward to seeing how researchers use them to address other fundamental questions related to musical diversity and evolution.

\subsection{Classical Music}

Perhaps the most unique thing about classical music as a research model for cultural evolution is the availability of historical notation. While records of orally transmitted folk music mostly begin with the 19th-century invention of the phonogram, notation of classical traditions such as Gregorian chant or Japanese gagaku can be traced back for over a millennium (Church, 2015). European "common practice" music since the 17th century is particularly richly documented (Taruskin, 2005). The Kunst der Fuge ${ }^{4}$ database, for example, has $~ 19,500$ full MIDI transcriptions that have been used to investigate everything from changes in harmonic complexity (Serra-Peralta et al., 2021) to statistical regularities in temporal structure

\footnotetext{
${ }^{2}$ https://www.themusiclab.org/nhs

${ }^{3}$ https://theglobaljukebox.org/

${ }^{4}$ https://www.kunstderfuge.com/
} 
(González-Espinoza et al., 2020). Other databases, like the Classical Music Navigator ${ }^{5}$ and ArkivMusic ${ }^{6}$, provide detailed information on composers' influences, geographic locations, and artistic styles that can be used to look at network topology (Park et al., 2015) and track the evolution of lineages (Georges, 2017). Below, we will briefly review some of the most notable research on the cultural evolution of classical music.

One of the most robust findings from studies of classical music is that distributions of melodic intervals change over time and are clearly clustered into well-known historical periods (Rodriguez Zivic et al., 2013; Weiß et al., 2019; Harasim et al., 2021). For example, the transition between the classical and romantic periods is characterized by great intervallic diversity and fewer transitions between adjacent notes (Rodriguez Zivic et al., 2013). The major and minor modes also appear to have changed over time, and are thought to have been preceded by multiple ancestors (Albrecht and Huron, 2014). Over larger time scales, both transcription and audio data have been used to conclude that factors like tonal complexity have increased over the history of Western classical music (Weiß et al., 2019; Serra-Peralta et al., 2021), possibly driven by a novelty bias for more rare musical events (Nakamura and Kaneko, 2019). Even individual composers appear to have greater maximum pitch fluctuations later on in the historical record (Liu et al., 2013). Jazz music also appears to have experienced an increase in tonal complexity and atypical chord transitions over time (Broze and Shanahan, 2013; Weiß et al., 2018). Interestingly, though, such long-term changes do appear to have some level of spatial variation. One study has shown that the perceived originality of popular classical music pieces has only increased in certain locations like Germany and Britain (Martindale and Uemura, 1983). Based on these well-documented increases in complexity, both Western classical and jazz music may deserve more attention as research models for cumulative cultural evolution moving forward.

Western classical music also has examples of popular compositions that have been performed, recorded, or transcribed many times by different people. Such cases can be ideal for phylogenetic analysis when variation is thought to reflect cultural transmission. The 16 different versions of Orlando Gibbon's "Prelude in G", for example, have slight variations like doubled and dotted notes that were introduced and spread during serial transcription (Windram et al., 2014). Similarly, different performances of Bach's sonatas for violin have variation in characteristics like chord ratios, vibrato, and tempo changes that appear to be clustered into recording periods (Liebman et al., 2012).

Research on the cultural evolution of classical music has historically been limited to the standard Western canon, likely due to a combination of researcher bias and data availability. There are many other rich traditions for which similarly detailed time-series data is increasingly available (Church, 2015). For example, the CompMusic project, led by Xavier Serra (2017), has recently released a set of corpora ${ }^{7}$ that include hundreds of transcriptions and recordings of classical music from India (Carnatic and Hindustani), North Africa (Arab-Andalusian), Turkey (makam), and China (jingju). There are also detailed data available for other understudied traditions like Gregorian chant (Cornelissen et al., 2020).

\subsection{Contemporary and Popular Music}

The immense amount of data available on contemporary music from online databases and streaming platforms make it particularly well-suited for cultural evolution research. Discogs, for example, has data from $\sim 14.5$ million releases by $~ 7.8$ million artists on its platform? ${ }^{9}$ Below, we will review some of the ways that researchers are using big data on contemporary music to test hypotheses about everything from population structure to diversity and complexity.

Certain music characteristics seem to be changing in diversity and complexity over time. In Western (US/UK) pop charts, lyrics are getting simpler (Varnum et al., 2021) and more negative (Napier and Shamir, 2018; Brand et al., 2019), even though the acoustic features of the most successful songs tend to be happier than the rest (Interiano et al., 2018). One study suggests that diversity in pitch transitions, timbre, and loudness is going down (Serrà et al., 2012; though see critique by Fink, 2013). However, others have found that diversity in contemporary music is either remaining relatively stable, based on pop charts that capture increasingly small fractions of global output and probably underestimate the trend (Mauch et al., 2015), or increasing, based on the rapid diversification of the communities of artists producing the music (electronic

\footnotetext{
${ }^{5}$ http://people.wku.edu/charles.smith/music/index2.htm

${ }^{6}$ https://www.arkivmusic.com/

${ }^{7}$ https://dunva.compmusic.upf.edu/

${ }^{8}$ http://www.globalchant.org/index.php

9 https://www.discogs.com/
} 
music: Youngblood et al., 2021; metal: Koch et al., 2020). Most recently, researchers found that changes in diversity over time vary greatly across genres, and that pop charts do in fact capture less diversity than broader corpora (Negro et al., 2022). Importantly, most of the studies above focused on Western pop charts, so it is unclear whether these patterns generalize to other cultural contexts ${ }^{10}$.

Temporal dynamics in diversity and complexity are likely mediated by a variety of factors. Genre diversification involves a great deal of competition (Koch et al., 2020), which seems to be intensifying in the age of digital media (Schneider and Gros, 2019). A rapid increase in media attention causes genres to diversify in the short-term, but too much media attention reduces the likelihood that new subgenres emerge (van Venrooij, 2015). The instrumental complexity of a genre increases with the number of artists involved, and yet it also dampens album sales (Percino et al., 2014). Additionally, songs from different genres appear to spread more rapidly through populations, likely depending on cultural context. For example, contagion models fit to song download data from Nokia cell phones in the UK between 2007 and 2014 show that electronic music spread much more rapidly than other genres during that time period (Rosati et al., 2021). We suspect that such variation in genre popularity over time and space is at least partly driven by fashion cycles (Acerbi et al., 2012). Recent research suggests that cycles in popular music styles since the 1950s are best explained by a counter-dominance process, where peripheral artists innovate novel and distinctive combinations of sounds that are dissimilar to more popular artists and eventually displace them (Klimek et al., 2019).

Transmission biases, which cause individuals to prefer certain cultural variants over others, also play a role in driving musical diversity over time. For example, popular drum breaks remain heavily sampled for longer than would be expected if artists were just copying them at random, and simulation-based inference indicates that this is due to a conformity bias within artist communities (Youngblood, 2019b). Additionally, the increase in the negative mood (Brand et al., 2019) and simplicity of pop lyrics described above may be consistent with content bias, where the strength of the simplicity advantage is higher when more novel choices are available (Varnum et al., 2021). Patterns of cultural turnover in other domains are less clear. Popular music charts appear to be dominated by random copying (Bentley et al., 2007) or novelty bias (Westenberger, 2021), whereas changes in music preferences on the platform Last.fm are consistent with either random copying or conformity depending on the scale (overall and within genres, respectively) (Acerbi and Bentley, 2014).

Contemporary music also has high-resolution collaboration data available that can be used to estimate population structure, which is rare in other research models of cultural evolution. Researchers have been constructing collaboration networks of music for decades (Gleiser and Danon, 2003; Guimerà et al., 2005; Teitelbaum et al., 2008), but they are increasingly being used for more formal hypothesis testing. In the last couple of years researchers have traced the cultural transmission of music samples through networks of hip-hop and electronic producers (Youngblood, 2019a), explored how mentorship and collaboration with elites influences the success of up-and-coming DJs (Janosov et al., 2020), and used a dynamic collaboration network to reconstruct a cultural phylogeny of electronic music (Youngblood et al., 2021). Other notable uses of network methods in research on contemporary music include mapping cover songs to determine the influence of different genres on one another (Ortega, 2021), and using the position of albums in an evolving co-occurrence network of user-generated tags to understand how heterogeneity and novelty influence popularity and cultural significance (Monechi et al., 2017).

Big data from the internet and social media also provide opportunities for natural experiments of musical behavior. For example, during the COVID-19 pandemic there has been a huge upsurge in virtual music making, sharing, and performance on platforms. Researchers were able to collect detailed data on these practices in real time (Hansen et al., 2021), and found that interest in "coronamusic" was the strongest predictor of socio-emotional coping included in their study (Fink et al., 2021). Another study, using data from Last.fm, found that live concerts give artists a temporary popularity boost among attendees that can spread to other users (Ternovski and Yasseri, 2020). As more music-focused apps like TikTok and Shazam make their data publicly available, there will be many more opportunities to track changes in music behavior in real-time.

It is important to acknowledge that big online datasets can have significant biases and limitations. Discogs has excellent coverage of electronic music but would be less appropriate for a study of classical or jazz music. Major streaming

\footnotetext{
${ }^{10}$ For a rare cross-cultural analysis of popular music, see Lee et al. (2021).
} 
platforms, like Spotify, often miss out on historical albums that were released on record labels that no longer have active distribution. The higher commercial value of popular music compared to folk or classical music means that researchers and companies may be less willing to share their data/algorithms, and even when they want to share them, copyright restrictions can mean that musical data either cannot be shared at all or only in limited forms. Researchers have begun to verify the quality of some music datasets (Lee et al., 2021), and employ methods for partial sharing of copyrighted music (extracted features: Bertin-Mahieux et al., 2011; short excerpts: Mehr et al., 2018; streaming audio: Wood et al., 2021), which will make it easier for others to consider the suitability and feasibility of different datasets for the questions they are asking.

\section{Experimental Approaches}

While there are many experimental studies of musical behavior and psychology, few have explicitly researched the cultural transmission and evolution of music in the lab. The handful of studies that have been done, though, have developed robust experimental methods that can be generalized to many unanswered questions related to transmission biases, transformation, and innovation processes.

Transmission chain designs, in which participants replicate a model (e.g. rhythm or melody) along a chain like a game of "telephone", are a particularly powerful method in the experimental toolkit (Mesoudi, this volume). By analyzing how rhythms or melodies change as they are passed between people, researchers can make inferences about the perceptual and cognitive processes that influence music evolution outside of the lab. When transmission chains are seeded with random drum sequences, for example, the sequences become more rhythmic and easier to learn as they are passed along the chain (Ravignani et al., 2017). Cross-cultural studies show that rhythms in transmission chains converge towards smaller integer ratios, with variation in the relative importance of ratios that appears to reflect local music structure (Jacoby and McDermott, 2017; Jacoby et al., 2021). This suggests that cognitive "priors" for simpler beats are universal, but the form of that simplicity is mediated by experience. Similarly, melodies appear to increase in regularity (e.g. smaller intervals moving in a single direction) when participants use them to communicate emotion to other participants (Lumaca and Baggio, 2017). A study using an artificial whistle system suggests that statistical universals in melodies, like rhythms, may also emerge from cultural evolution due to cognitive biases (Verhoef and Ravignani, 2021). Importantly, though, these cognitive priors are not uniform across individuals. If you run transmission chains with single participants the sequences converge more quickly but are less reflective of rhythmic universals (Ravignani et al., 2018). They may also be shaped by factors other than perception, for example, physical distances between drums impose motor constraints on the kinds of rhythms that are likely to emerge (Miton et al., 2020).

Artificial evolution and market studies, in which participants choose between songs or sounds, have also led to important insights. In their "DarwinTunes" study, MacCallum et al. (2012) designed an experiment where the survival of mutating and reproducing audio loops were determined by participants' aesthetic preferences. The audio loops rapidly evolved to have more structured melodic and rhythmic content before stabilizing at an intermediate level of complexity. Market studies, on the other hand, have focused more on the role of social information in musical success. In one such study, researchers tracked the success of songs when participants either did or did not have access to download counts (Salganik et al., 2006). Social information amplified the popularity of music that was already perceived as popular, causing success to be more unequal and unpredictable. Perceived popularity continued to drive success in this way even when download counts were experimentally inverted (Salganik and Watts, 2008), although some songs that were rated as "high quality" by participants did recover from the inversion. In another study, the perceived quality of songs was positively influenced by the perceived prestige of performers (Anglada-Tort and Müllensiefen, 2017).

\section{4. "Music-Like" Song in Non-Human Animals}

In recent decades a great deal of work has been done on the cultural evolution of learned vocalizations in non-human animals, particularly bird and whale song (Aplin, this volume; Garland and Rendell, this volume), which have some remarkable similarities with human music (Gray et al., 2001; Fitch, 2006; Rohrmeier et al., 2015). For example, some bird songs have rhythmic and melodic properties such as gradual pitch escalations (Rothenberg et al., 2014), categorical integer ratios for rhythms (Roeske et al., 2020) and scales (Doolittle et al., 2014), and multifractal structure (Roeske et al. 2018). 
Humpback whales also have hierarchical rhythmic structures that are like those found in human music (Handel et al., 2009; Kello et al., 2017). Additionally, bird song and human music appear to be shaped by similar motor constraints (Savage et al., 2017; Tierney et al., 2011; Ammirante and Russo, 2015), and when bird songs are shuffled they are less likely to be classified as "musical" by human listeners (Bilger et al., 2021). Below, we will briefly review research on the cultural evolution of non-human song relevant to cultural evolution researchers. Specifically, we will focus on three insights from research on the cultural evolution of non-human song: (1) the utility of detailed agent-based models of social learning, (2) the dual importance of biased transmission and transformation, and (3) the role of ecological factors in cultural selection.

Agent-based models of non-human social learning are often quite detailed, including parameters for innovation and cognitive biases alongside life history processes like birth, dispersal, reproduction, migration, and mortality. By comparing these models with real datasets, either descriptively or within a statistical framework like approximate Bayesian computation, researchers can make inferences about the processes that influence the evolution of non-human song. In birds, such models have been used to investigate the emergence of local dialects (Strigul, 2009), the effect of dispersal on song diversity (Ellers and Slabbekoorn, 2003), drivers of context-dependence in song syntax (Katahira et al., 2011; Morita et al., 2021), and the influence of transmission biases on population-level cultural diversity (Lachlan et al., 2018; Youngblood and Lahti, 2022). In whales, researchers have used such models to highlight the importance of shared breeding grounds on song evolution (Mcloughlin et al., 2018; Zandberg et al., 2021), explore how different life history characteristics interact in driving dialects (Filatova and Miller, 2015), and investigate the effect of conformity and homophily in stabilizing structural patterns (Cantor et al., 2015). In the domain of human music, detailed longitudinal data on factors like network structure and population turnover are much more easily available and yet are often not included in models of social learning (Youngblood, 2019b). Future studies should integrate such data into more complex agent-based models to make better inferences about processes driving the cultural evolution of music.

Historically, the relative importance of biased transmission between individuals and transformation within individuals has been hotly debated (Mesoudi, 2021), but it now seems clear that both play critical roles in the cultural evolutionary process. Transformation in cultural evolution can take many forms and includes processes that have been heavily studied in songbirds, such as innate learning biases and constraints that lead to convergence in cultural forms. For example, when song sparrows are tutored with heterospecific syllables, they incorporate them into repeated trill sequences to be more species-typical (Marler and Peters, 1988). Such modifications also occur with conspecific song. When swamp sparrows are tutored with experimentally slowed trills they sacrifice transmission fidelity to sing them at a higher rate (Lahti et al., 2011). Zebra finches that are separately tutored with randomized syllable sequences converge towards similar sequences with alternating pitches (James and Sakata, 2017). These kinds of biases cause groups of either isolate birds with atypical song, or groups of birds tutored with heterospecific song, to evolve towards wild type song in just a few generations (Fehér et al., 2009; Diez and MacDougall-Shackleton, 2020). Based on some of the experimental studies described earlier in the chapter it is quite likely that transformative processes play an important role in human music as well, but it is notoriously difficult to separate the influence of biased transmission from transformation. Luckily, there are some new modeling (Acerbi et al., 2021; Mesoudi, 2021; Falandays and Smaldino, 2021) and empirical (Strachan et al., 2021) methods that may facilitate future study of transformative processes in music.

Studies of non-human song have also highlighted the role of ecological (i.e. non-psychological) factors in cultural selection, which has only recently begun to be explored in human music (Miton et al., 2020; Scott-Phillips et al., 2021). By far the most heavily researched ecological factor that influences non-human song is anthropogenic noise, which is a serious conservation concern for both bird and whale populations. Noise in the urban environment usually has the highest energy at lower frequencies, and as a result birds in urban areas sometimes sing with a higher minimum frequency to avoid masking (Slabbekoorn, 2013). In some species this appears to be a plastic response where individual shift up the pitch of their syllables in real time (Bermúdez-Cuamatzin et al., 2011), whereas in others it is because juveniles are more likely to learn songs that are easier to hear in noisy conditions (Moseley et al., 2018). During the COVID-19 pandemic, reductions in urban noise allowed white-crowned sparrows in San Francisco to sing at lower pitches again (Derryberry et al., 2020). Noise from boats, sonar, and seismic airguns has similar effects in the ocean, causing different whale species to shift the pitch, duration, and rate of their singing (Miller et al., 2000; Foote et al., 2004; Parks et al., 2007; Castellote et al., 2012; Risch et al., 2012). Compared to non-human song, there are many more ecological factors that have the potential to influence 
human music, some of which themselves result from cultural evolution (such as instrument structure and social context) (Miton et al., 2020). The effects of such factors on musical change are both interesting in their own right and likely to be confounded with other processes if not accounted for. We hope that more researchers will investigate the influence of ecological factors on music so that we can better understand how psychology and the environment interact in driving cultural evolution.

\section{Applications}

In some non-human species, socially-learned behaviors such as song are critically important for survival and/or reproduction. Because of this, cultural evolution is increasingly being considered in animal conservation efforts (Brakes et al., 2019; 2021). Although there are, of course, key differences between non-human song and human music, we think that research on cultural evolution may also improve our ability to fight musical endangerment ${ }^{11}$ (Savage, 2017). Genres, the units of musical diversity thought to be most relevant for conservation (Grant, 2014), are notoriously difficult to identify due to their fuzzy boundaries and hierarchical structures. Methods from cultural evolutionary research based on auditory similarity (Mauch et al., 2015), instrument co-occurrence (Percino et al., 2014), and community structure (Youngblood et al., 2021) could be used to distinguish between neighboring genres and assess their relative endangerment, based on population size and other factors. Additionally, cultural evolutionary theory provides a framework for understanding the coevolution of different cultural practices, which often reinforce and stabilize one another. Music, for example, contains a great deal of linguistic information and can be used to assist in language conservation (Grant, 2014; da Fonseca-Wollheim, 2016; Muyiwa, 2021). Lastly, musical endangerment is a complex, ecological problem with dynamic interdependencies that make it difficult to predict the outcomes of proposed solutions (Grant, 2015). Agent-based models from cultural evolution that simulate the stochasticity and unseen interdependencies found in real systems may improve our ability to design effective interventions for musical conservation.

The same sequence alignment method used to assess similarity in folk melodies, described above (Savage and Atkinson, 2015), has already been adapted for use in copyright infringement cases (Savage et al., 2018). Such methods could also be used to identify music samples and cover songs (Serrà et al., 2010; Yuan et al., 2020) so that original artists are automatically reimbursed when their work is adapted by other artists. Importantly, though, these kinds of technologies need to take convergence into account and respect artist communities for whom covering and sampling is a common practice (Seeger, 1992; Youngblood, 2019a; Youngblood 2019b). Automated detection methods are likely to have a high risk of false positives, especially when broadly applied in a "preventative" way like Spotify's recently developed AI (Smith, 2020). Current trends in music production, such as cloud-based sample and preset libraries ${ }^{12}$ and generative composition algorithms ${ }^{13}$, may increase convergence within some artist communities and compound this issue. False positives could be reduced by combining automated detection methods with a cultural evolution model that predicts which musical similarities are likely to be convergent (as opposed to directly copied). Such methods could also be used to fairly compensate original artists when their work is adapted by other artists, by automatically identifying covers and samples and collecting a profit percentage (similar to the "up-front" sampling model used by Tracklib ${ }^{14}$ ).

Methods from the cultural evolution of music also have the potential to improve recommendation algorithms used by streaming platforms. For example, the "fans also like" recommendation algorithm used by Spotify is mostly based on existing listening habits of fans and the co-occurence of artist names on blogs and social media (Johnston, 2019). Such algorithms can lead to "filter bubbles" that reduce the diversity of music consumed by the average listener (Anderson et al., 2020), and compound the existing "rich get richer" dynamics of the music industry (Abdollahpouri and Mansoury, 2020; Abdollahpouri et al., 2020; Werner, 2020; O'Dair and Fry, 2020; even through payola, see Hern, 2020). Network-based methods that estimate the structure of real artist communities and track how they change over time (Youngblood, 2019a; Youngblood et al., 2021) could mitigate these issues by providing platforms with a way to identify new related artists that are not already being listened to by fans of established artists (indeed, this was part of the motivation behind Lomax's

\footnotetext{
${ }^{11}$ A map of endangered musical traditions from around the world can be found here: http://www.musicendangerment.com/map/

${ }^{12}$ https://splice.com/

${ }^{13} \underline{\mathrm{https}: / / \text { openai.com/blog/musenet/ }}$

${ }^{14}$ https://www.tracklib.com/
} 
Cantometrics Project and Pandora's Music Genome Project that it inspired; Abromeit, 2012). Similarly, the kinds of agent-based models used in cultural evolution research could be used to simulate different algorithmic configurations and avoid those that lead to disadvantageous outcomes for artists and listeners. Both of the above recommendations, though, are double-edged swords and must be paired with appropriate ethical considerations (e.g. algorithmic transparency legislation) to ensure that new technologies improve rather than reinforce existing systemic injustices (Noble, 2018).

\section{Conclusion}

The study of the cultural evolution of music is attracting increasing interest from a diverse array of fields including cognitive science, computational social science, and behavioral ecology, but it is still very much in its early stages. Searching for \{“cultural evolution" AND "music"\} in the Web of Science Core Collection yields only 63 results by 126 authors, most of which have been published since 2018. Despite its youth, the study of the cultural evolution of music has resulted in some important insights. For example, research on traditional and folk music have revealed that scales around the world have a tendency to converge towards similar patterns, musical variation is correlated with social complexity and sometimes population history, and that certain styles of music are reliably associated with particular behavioral contexts across cultures according to their acoustic features. Studies of classical music have found that melodic intervals are associated with particular historical periods, and that tonal complexity and harmonic richness have increased over time. Studies of contemporary and popular music have tracked changes in a variety of music characteristics such as diversity, loudness, and the emotional valence of lyrics, and have used detailed information on population structure and the distribution of cultural variants to try to understand the processes underlying such changes. Experimental approaches have shown that rhythms and melodies increase in regularity over the course of transmission in a manner that is consistent with universal cognitive priors that are mediated by both individual experience and external factors. Finally, studies on "music-like" song in non-human species highlight the importance of further emphasizing demographic processes, transformation, and ecological factors in future studies of the cultural evolution of music.

In conclusion, we feel that cultural evolution researchers have barely scratched the surface of the available musical datasets and methodologies. For example, there is a rich literature on music information retrieval, including automated methods for extracting pitch and rhythm (Benetos et al., 2019; Ozaki et al., 2021), that has yet to be fully leveraged for studies of cultural evolution. There are also opportunities for research on music to inform broader questions relevant to the field of cultural evolution, such as the coevolution of music, dance, and ritual in religion (Norenzayan et al., 2016; Sterelny, 2018), shared mechanisms in the development of music, language, and non-human song (Fitch, 2006; Rohrmeier et al., 2015), analogies between genetic and "memetic" transmission (Hoeschele and Fitch, 2022; Laland and Brown, 2011), and the role of cumulative cultural evolution in aesthetic domains (Sinclair et al., 2022). As researchers continue to collaborate across disciplinary boundaries and take advantage of the diversity of perspectives and approaches from different communities (Jacoby et al., 2020), we think that music has the potential to become a powerful research model for cultural evolution.

\section{References}

Abdollahpouri, H., and Mansoury, M. (2020). Multi-sided exposure bias in recommendation. arXiv. http://arxiv.org/abs/2006.15772

Abdollahpouri, H., Mansoury, M., Burke, R., and Mobasher, B. (2020). Addressing the multistakeholder impact of popularity bias in recommendation through calibration. arXiv. https://arxiv.org/abs/2007.12230

Abromeit, K. A. (2012). Association for cultural equity. Music Reference Services Quarterly, 15(3), 211-214. https://doi.org/10.1080/10588167.2012.700204

Acerbi, A., and Bentley, R. A. (2014). Biases in cultural transmission shape the turnover of popular traits. Evolution and Human Behavior, 35(3), 228-236. https://doi.org/10.1016/j.evolhumbehav.2014.02.003

Acerbi, A., Charbonneau, M., Miton, H., and Scott-Phillips, T. (2021). Culture without copying or selection. Evolutionary Human Sciences, 3(e50). https://doi.org/10.1017/ehs.2021.47

Acerbi, A., Ghirlanda, S., and Enquist, M. (2012). The logic of fashion cycles. PLOS ONE, 7(3), e32541. https://doi.org/10.1371/iournal.pone.0032541

Aguirre-Fernández, G., Blasi, D. E., and Sánchez-Villagra, M. R. (2020). Panpipes as units of cultural analysis and dispersal. Evolutionary Human Sciences, 2,1-11. https://doi.org/10.1017/ehs.2020.15

Albrecht, J. D., and Huron, D. (2014). A statistical approach to tracing the historical development of major and minor pitch distributions, $1400-1750$. Music Perception, 31(3), 223-243. https://doi.org/10.1525/mp.2014.31.3.223

Ammirante, P., and Russo, F. A. (2015). Low-skip bias: The distribution of skips across the pitch ranges of vocal and instrumental melodies is vocally constrained. Music Perception, 32(4), 355-363. 
Anderson, A., Maystre, L., Anderson, I., Mehrotra, R., and Lalmas, M. (2020). Algorithmic effects on the diversity of consumption on Spotify. Proceedings of the World Wide Web Conference, WWW 2020, 2, 2155-2165. https://doi.org/10.1145/3366423.3380281

Anglada-Tort, M., and Müllensiefen, D. (2017). The repeated recording illusion: the effects of extrinsic and individual difference factors on musical judgments. Music Perception, 35(1), 94-117. https://doi.org/10.1525/mp.2017.35.1.24

Aplin, A. (this volume). Culture in birds. In R. Kendal, J. J. Tehrani, and J. Kendal (Eds.), Oxford Handbook of Cultural Evolution. Oxford University Press.

Bailes, R. and Cuskley (this volume). Cultural evolution of language. In R. Kendal, J. J. Tehrani, and J. Kendal (Eds.), Oxford Handbook of Cultural Evolution. Oxford University Press.

Benetos, E., Dixon, S., Duan, Z., and Ewert, S. (2019). Automatic music transcription: An overview. IEEE Signal Processing Magazine, 36(1), 20-30. https://doi.org/10.1109/MSP.2018.2869928

Bentley, R. A., Lipo, C. P., Herzog, H. A., and Hahn, M. W. (2007). Regular rates of popular culture change reflect random copying. Evolution and Human Behavior, 28(3), 151-158. https://doi.org/10.1016/i.evolhumbehav.2006.10.002

Bermúdez-Cuamatzin, E., Ríos-Chelén, A. A., Gil, D., and Garcia, C. M. (2011). Experimental evidence for real-time song frequency shift in response to urban noise in a passerine bird. Biology Letters, 7, 36-38. https://doi.org/10.1098/rsbl.2010.0437

Bertin-Mahieux, T., Ellis, D. P. W., Whitman, B., and Lamere, P. (2011). The million song dataset. Proceedings of the 12th International Society for Music Information Retrieval Conference (ISMIR 2011), 591-596.

Bilger, H. T., Vertosick, E., Vickers, A., Kaczmarek, K., and Prum, R. O. (2021). Higher-order musical temporal structure in bird song. Frontiers in Psychology, 12. https://doi.org/10.3389/fpsyg.2021.629456

Brand, C. O., Acerbi, A., and Mesoudi, A. (2019). Cultural evolution of emotional expression in 50 years of song lyrics. Evolutionary Human Sciences, 1(e11). https://doi.org/10.1017/ehs.2019.11

Brakes, P., Carroll, E. L., Dall, S. R. X., Keith, S. A., McGregor, P. K., Mesnick, S. L., Noad, M. J., Rendell, L., Robbins, M. M., Rutz, C., Thornton, A., Whiten, A., Whiting, M. J., Aplin, L. M., Bearhop, S., Ciucci, P., Fishlock, V., Ford, J. K. B., Notarbartolo Di Sciara, G., ... Garland, E. C. (2021). A deepening understanding of animal culture suggests lessons for conservation. Proceedings of the Royal Society B: Biological Sciences, 288, 20202718. https://doi.org/10.1098/rspb.2020.2718

Brakes, P., Dall, S. R. X., Aplin, L. M., Bearhop, S., Carroll, E. L., Ciucci, P., Fishlock, V., Ford, J. K. B., Garland, E. C., Keith, S. A., McGregor, P. K., Mesnick, S. L., Noad, M. J., Notarbartolo di Sciara, G., Robbins, M. M., Simmonds, M. P., Spina, F., Thornton, A., Wade, P. R., ... Rutz, C. (2019). Animal cultures matter for conservation. Science, 363(6431), 1032-1034. https://doi.org/10.1126/science.aaw3557

Bronson, B. H. (1969). The Ballad as Song. University of California Press.

Brown, D. (1991). Human Universals. New York: McGraw-Hill.

Brown, S. (2000). The 'musilanguage' model of music evolution. In Wallin, N. L., Merker, B., Brown, S. (Eds.), The Origins of Music (pp. 271-300). Cambridge, MA: MIT Press.

Brown, S., and Jordania, J. (2013). Universals in the world's musics. Psychology of Music, 41(2), 229-248. https://doi.org/10.11777/0305735611425896.

Brown, S., Savage, P. E., Ko, A. M.-S., Stoneking, M., Ko, Y.-C., Loo, J.-H., and Trejaut, J. A. (2014). Correlations in the population structure of music, genes and language. Proceedings of the Royal Society B: Biological Sciences, 281(1774), 20132072. https://doi.org/10.1098/rspb.2013.2072

Broze, Y., and Shanahan, D. (2013). Diachronic changes in jazz harmony. Music Perception, 31(1), 32-45. https://doi.org/10.1525/mp.2013.31.1.32

Cantor, M., Shoemaker, L. G., Cabral, R. B., Flores, C. O., Varga, M., and Whitehead, H. (2015). Multilevel animal societies can emerge from cultural transmission. Nature Communications, 6. https://doi.org/10.1038/ncomms 9091

Castellote, M., Clark, C. W., and Lammers, M. O. (2012). Acoustic and behavioural changes by fin whales (Balaenoptera physalus) in response to shipping and airgun noise. Biological Conservation, 147(1), 115-122. https://doi.org/10.1016/i.biocon.2011.12.021

Church, M. (Ed.). (2015). The Other Classical Musics: Fifteen Great Traditions. Boydell Press.

Cornelissen, B., Zuidema, W., and Burgoyne, J. A. (2020). Mode classification and natural units in plainchant. Proceedings of the 21st International Society for Music Information Retrieval Conference (ISMIR 2020), 869-875.

da Fonseca-Wollheim, C. (2016). Vanishing languages, reincarnated as music. The New York Times. https:/www.nytimes.com/2016/04/03/arts/music/vanishing-languages-reincarnated-as-music.html

Darwin, C. (1871). The Descent of Man, and Selection in Relation to Sex. John Murray.

Derryberry, E. P., Phillips, J. N., Derryberry, G. E., Blum, M. J., and Luther, D. (2020). Singing in a silent spring: Birds respond to a half-century soundscape reversion during the COVID-19 shutdown. Science, 6516, 575-579. https://doi.org/10.1126/science.abd5777

Deutsch, D., Henthorn, T., and Lapidis, R. (2011). Illusory transformation from speech to song. The Journal of the Acoustical Society of America, 129(4), 2245-2252. https://doi.org/10.1121/1.3562174

Díaz-Báñez, M., Farigu, G., Gómez, F., Rappaport, D., and Toussaint, G. T. (2004). El compás flamenco: a phylogenetic analysis. Proceedings of BRIDGES: Mathematical Connections in Art, Music and Science, 61-70.

Diez, A., and MacDougall-Shackleton, S. A. (2020). Zebra finches go wild! Experimental cultural evolution of birdsong. Behaviour, 157(3-4), 231-265. https://doi.org/10.1163/1568539X-00003588

Dissanayake, E. (2000). Antecedents of the temporal arts in early mother-infant interaction. In N. L. Wallin, B. Merker, and S. Brown (Eds.), The Origins of Music. MIT Press.

Doolittle, E. L., Gingras, B., Endres, D. M., and Fitch, W. T. (2014). Overtone-based pitch selection in hermit thrush song: Unexpected convergence with scale construction in human music. Proceedings of the National Academy of Sciences of the United States of America, 111(46), 16616-16621. https://doi.org/10.1073/pnas.1406023111

Ellers, J., and Slabbekoorn, H. (2003). Song divergence and male dispersal among bird populations: a spatially explicit model testing the role of vocal learning. Animal Behaviour, 65(4), 671-681. https://doi.org/10.1006/anbe.2003.2081

Engelhardt, J., and Bretèque, E. A. de la. (2017). Guest editors' preface: speech, song, and in-between. Yearbook for Traditional Music, 49, xv-xix. https://doi.org/10.5921/yeartradmusi.49.2017.00xv

Falandays, J. B., and Smaldino, P. E. (2021). The emergence of cultural attractors: how dynamic populations of learners achieve collective cognitive alignment. PsyArXiv. https:/psyarxiv.com/v5fsr/

Fehér, O., Wang, H., Saar, S., Mitra, P. P., and Tchernichovski, O. (2009). De novo establishment of wild-type song culture in the zebra finch. Nature, 459(7246), 564-568. https://doi.org/10.1038/nature07994 
Feld, S., and Fox, A. A. (1994). Music and language. Annual Review of Anthropology, 23, 25-53.

Filatova, O. A., and Miller, P. J. O. (2015). An agent-based model of dialect evolution in killer whales. Journal of Theoretical Biology, 373, 82-91. https://doi.org/10.1016/i.jtbi.2015.03.020

Fink, R. (2013). Big (bad) data. Musicology Now. http://musicologynowams-net.org/2013/08/big-bad-data.html

Fink, L. K., Warrenburg, L. A., Howlin, C., Randall, W. M., Hansen, N. C., and Wald-Fuhrmann, M. (2021). Viral tunes: changes in musical behaviours and interest in coronamusic predict socio-emotional coping during COVID-19 lockdown. Humanities and Social Sciences Communications, 8(180), 1-11. https://doi.org/10.1057/s41599-021-00858-y

Fitch, W. T. (2006). The biology and evolution of music: a comparative perspective. Cognition, 100(1), 173-215. https://doi.org/10.1016/i.cognition.2005.11.009

Foote, A. D., Osborne, R. W., and Hoelzel, A. R. (2004). Whale-call response to masking boat noise. Nature, 428(6986), 910. https://doi.org/10.1038/428910a

Garland, E. C., and Rendell, L. (this volume). Culture in cetaceans. In R. Kendal, J. J. Tehrani, and J. Kendal (Eds.), Oxford Handbook of Cultural Evolution. Oxford University Press.

Georges, P. (2017). Western classical music development: a statistical analysis of composers similarity, differentiation and evolution. Scientometrics, 112, 21-53. https://doi.org/10.1007/s11192-017-2387-x

Gleiser, P. M., and Danon, L. (2003). Community structure in jazz. Advances in Complex Systems, 6(4), 565-573. https://doi.org/10.1142/s0219525903001067

González-Espinoza, A., Martínez-Mekler, G. and Lacasa, L. (2020). Arrow of time across five centuries of classical music. Physical Review Research, 2(3), 033166. https://doi.org/10.1103/PhysRevResearch.2.033166

Grant, C. (2014). Music Endangerment: How Language Maintenance Can Help. Oxford University Press. https://doi.org/10.1080/17411912.2014.1003076

Grant, C. (2015). Endangered musical heritage as a wicked problem. International Journal of Heritage Studies, 21(7), 629-641. https://doi.org/10.1080/13527258.2014.976245

Gray, P. M., Krause, B., Atema, J., Payne, R., Krumhansl, C., and Baptista, L. (2001). The music of nature and the nature of music. Science, 291(5501), 52-54. https://doi.org/10.1126/science.10.1126/SCIENCE. 1056960

Guimerà, R., Uzzi, B., Spiro, J., and Nunes Amaral, L. A. (2005). Team assembly mechanisms determine collaboration network structure and team performance. Science, 308(5722), 697-702. https://doi.org/10.1126/science.1106340

Handel, S., Todd, S. K., and Zoidis, A. M. (2009). Rhythmic structure in humpback whale (Megaptera novaeangliae) songs: Preliminary implications for song production and perception. The Journal of the Acoustical Society of America, 125(6), EL225-EL230. https://doi.org/10.1121/1.3124712

Hansen, N. C., Treider, J. M. G., Swarbrick, D., Bamford, J. S., Wilson, J., and Vuoskoski, J. K. (2021). A crowd-sourced database of coronamusic: documenting online making and sharing of music during the COVID-19 pandemic. Frontiers in Psychology, 12, 684083. https://doi.org/10.3389/fpsyg. 2021.684083

Harasim, D., Moss, F.C., Ramirez, M., Ramirez, M. and Rohrmeier, M. (2021). Exploring the foundations of tonality: statistical cognitive modeling of modes in the history of Western classical music. Humanities and Social Sciences Communications, $8(5)$. https://doi.org/10.1057/s41599-020-00678-6.

Hern, A. (2020). Spotify to let artists promote music for cut in royalty rates. The Guardian. https://www.theguardian.com/technology/2020/nov/03/spotify-artists-promote-music-exchange-cut-royalty-rates-payola-algorithm

Hilton, C. B., Thierry, L. C., Yan, R., Martin, A., and Mehr, S. A. (2021). Children infer the behavioral contexts of unfamiliar foreign songs. Psy Arxiv. https://doi.org/10.31234/osf.io/rz6qn

Hoeschele, M., and Fitch, W. T. (in press). Cultural evolution: melodic evolution obeys the same constraints across musical cultures. Current Biology.

Honing, H. (2018). Musicality as an upbeat to music: introduction and research agenda. In H. Honing (Ed.), The Origins of Musicality. Cambridge, MA: MIT Press.

Honing, H., ten Cate, C., Peretz, I., and Trehub, S. E. (2015). Without it no music: cognition, biology and evolution of musicality. Philosophical Transactions of the Royal Society B, 370, 20140088. http://doi.org/10.1098/rstb.2014.0088

Interiano, M., Kazemi, K., Wang, L., Yang, J., Yu, Z., and Komarova, N. L. (2018). Musical trends and predictability of success in contemporary songs in and out of the top charts. Royal Society Open Science, 5(5). https://doi.org/10.1098/rsos.171274

International Folk Music Council. (1955). Resolutions: definition of folk music. Journal of the International Folk Music Council, 7, 23.

Jacoby, N., Margulis, E. H., Clayton, M., Hannon, E., Honing, H., Iversen, J., Klein, T. R., Mehr, S. A., Pearson, L., Peretz, I., Perlman, M., Polak, R., Ravignani, A., Savage, P. E., Steingo, G., Stevens, C. J., Trainor, L., Trehub, S., Veal, M., and Wald-Fuhrmann, M. (2020). Cross-cultural work in music cognition: Challenges, insights, and recommendations. Music Perception, 37(3), 185-195. https://doi.org/10.1525/MP.2020.37.3.185

Jacoby, N., and McDermott, J. H. (2017). Integer ratio priors on musical rhythm revealed cross-culturally by iterated reproduction. Current Biology, 27(3), 359-370. https://doi.org/10.1016/i.cub.2016.12.031

Jacoby, N., Polak, R., Grahn, J. A., Cameron, D. J., Lee, K. M., Godoy, R., Undurraga, E. A., Huanca, T., Thalwitzer, T., Doumbia, N., Goldberg, D., Margulis, E., Wong, P. C. M., Jure, L., Rocamora, M., Fujii, S., Savage, P. E., Ajimi, J., Konno, R., ... McDermott, J. H. (2021). Universality and cross-cultural variation in mental representations of music revealed by global comparison of rhythm priors. PsyArXiv. https://doi.org/10.31234/osf.io/b879v

James, L. S., and Sakata, J. T. (2017). Learning biases underlie “universals" in avian vocal sequencing. Current Biology, 27(23), 3676-3682. https://doi.org/10.1016/i.cub.2017.10.019

Janosov, M., Musciotto, F., Battiston, F., and Iñiguez, G. (2020). Elites, communities and the limited benefits of mentorship in electronic music. Scientific Reports, 10(1), 3136. https://doi.org/10.1038/s41598-020-60055-w

Johnston, M. (2019). How "fans also like" works. https://artists.spotify.com/blog/how-fans-also-like-works

Katahira, K., Suzuki, K., Okanoya, K., and Okada, M. (2011). Complex sequencing rules of birdsong can be explained by simple hidden Markov processes. PLoS ONE, 6(9). https://doi.org/10.1371/journal.pone.0024516

Kello, C. T., Bella, S. D., Médé, B., and Balasubramaniam, R. (2017). Hierarchical temporal structure in music, speech and animal vocalizations: Jazz is like a conversation, humpbacks sing like hermit thrushes. Journal of the Royal Society Interface, 14(135). https://doi.org/10.1098/rsif.2017.0231 
Klimek, P., Kreuzbauer, R., and Thurner, S. (2019). Fashion and art cycles are driven by counter-dominance signals of elite competition: Quantitative evidence from music styles. Journal of The Royal Society Interface, 16(151), 20180731. https://doi.org/10.1098/rsif.2018.0731

Koch, B., Silvestro, D., and Foster, J. (2020). The evolutionary dynamics of cultural change (as told through the birth and brutal, blackened death of metal music). SocArXiv. https://doi.org/10.31235/osfio/659bt

Kuroyanagi, J., Sato, S., Ho, M.-J., Chiba, G., Six, J., Pfordresher, P., Tierney, A., Fujii, S., and Savage, P. E. (2019). Automatic comparison of human music, speech, and bird song suggests uniqueness of human scales. Proceedings of the 9th International Workshop on Folk Music Analysis (FMA2019), 35-40. https://doi.org/10.31234/osf.io/zpv5w

Lachlan, R. F., Ratmann, O., and Nowicki, S. (2018). Cultural conformity generates extremely stable traditions in bird song. Nature Communications, 9. https://doi.org/10.1038/s41467-018-04728-1

Lahti, D. C., Moseley, D. L., and Podos, J. (2011). A tradeoff between performance and accuracy in bird song learning. Ethology, $117(9), 802-811$. https://doi.org/10.1111/i.1439-0310.2011.01930.x

Laland, K. N., and Brown, G. R. (2011). Sense and Nonsense: Evolutionary Perspectives on Human Behaviour (2nd ed.). Oxford University Press.

Le Bomin S., Lecointre, G., and Heyer, E. (2016). The evolution of musical diversity: the key role of vertical transmission. PLoS ONE, 11 (3), e0151570. https:// doi.org/10.1371/journal.pone. 0151570

Lee, H., Höger, F., Schönwiesner, M., Park, M., and Jacoby, N. (2021). Cross-cultural mood perception in pop songs and its alignment with mood detection algorithms. Proceedings of the 22nd International Society for Music Information Retrieval Conference, 366-373. https://doi.org/10.5281/zenodo.5625680

Liebman, E., Ornoy, E. and Chor, B. (2012). A phylogenetic approach to music performance analysis. Journal of New Music Research, 41(2), $195-222$. https://doi.org/10.1080/09298215.2012.668194

Liu, L., Wei, J., Zhang, H., Xin, J., and Huang, J. (2013). A statistical physics view of pitch fluctuations in the classical music from Bach to Chopin: evidence for scaling. PLoS ONE, 8(3), e58710. https://doi.org/10.1371/journal.pone.0058710

Lomax, A. (1968). Folk Song Style and Culture. Washington, DC: American Association for the Advancement of Science.

Lomax, A. (1980). Factors of musical style. In: Diamond, S. (Ed.) Theory and Practice: Essays Presented to Gene Weltfish (pp. 29-58). The Hague: Mouton.

Lomax, A., and Berkowitz, N. (1972). The evolutionary taxonomy of culture. Science, 177(4045), 228-239. https://doi.org/10.1126/science.177.4045.228

Lumaca, M., and Baggio, G. (2017). Cultural transmission and evolution of melodic structures in multi-generational signaling games. Artificial Life, 23, 406-423. https://doi.org/10.1162/ARTL a 00238

MacCallum, R. M., Mauch, M., Burt, A., and Leroi, A. M. (2012). Evolution of music by public choice. Proceedings of the National Academy of Science, 109(30), 12081-12086. https://doi.org/10.1073/pnas.1203182109

Marler, P., and Peters, S. (1988). The role of song phonology and syntax in vocal learning preferences in the song sparrow, Melospiza melodia. Ethology, 77 , 125-149.

Martindal, C. and Uemura, A. (1983). Stylistic evolution in European music. Leonardo, 16(3), 225-228.

Matsumae, H., Ranacher, P., Savage, P. E., Blasi, D. E., Currie, T. E., Koganebuchi, K., Nishida, N., Sato, T., Tanabe, H., Tajima, A., Brown, S., Stoneking, M., Shimizu, K. K., Oota, H., and Bickel, B. (2021). Exploring correlations in genetic and cultural variation across language families in Northeast Asia. Science Advances, 7(34). https://doi.org/10.1126/sciadv.abd9223

Mauch, M., Maccallum, R. M., Levy, M., and Leroi, A. M. (2015). The evolution of popular music: USA 1960-2010. Royal Society Open Science, 2. https://doi.org/10.1098/rsos. 150081

McBride, J. M., and Tlusty, T. (2019). Cross-cultural data shows musical scales evolved to maximise imperfect fifths. arXiv. https://doi.org/10.31234/osf.io/a97x4

McBride, J. M., and Tlusty, T. (2021). Convergent evolution in a large cross-cultural database of musical scales. arXiv. http://arxiv.org/abs/2108.00842

Mcloughlin, M., Lamoni, L., Garland, E. C., Ingram, S., Kirke, A., Noad, M. J., Rendell, L., and Miranda, E. (2018). Using agent-based models to understand the role of individuals in the song evolution of humpback whales (Megaptera novaeangliae). Music and Science, 1, 1-17. https://doi.org/10.1177/2059204318757021

Mesoudi, A. (2011). Cultural Evolution: How Darwinian Theory Can Explain Human Culture and Synthesize the Social Sciences. Chicago, IL: University of Chicago Press.

Mesoudi, A. (2021). Cultural selection and biased transformation: two dynamics of cultural evolution. Philosophical Transactions of the Royal Society B: Biological Sciences, 376(1828). https://doi.org/10.1098/rstb.2020.0053

Mesoudi, A. (this volume). Experimental studies of cultural evolution. In R. Kendal, J. J. Tehrani, and J. Kendal (Eds.), Oxford Handbook of Cultural Evolution. Oxford University Press.

Mehr, S. A., Krasnow, M., Bryant, G., and Hagen, E. (2021). Origins of music in credible signaling. Behavioral and Brain Sciences, 44 , E60. https://doi.org/10.1017/S0140525X20000345

Mehr, S. A., Singh, M., Knox, D., Ketter, D. M., Pickens-Jones, D., Atwood, S., Lucas, C., Jacoby, N., Egner, A. A., Hopkins, E. J., Howard, R. M., Hartshorne, J. K., Jennings, M. V., Simson, J., Bainbridge, C. M., Pinker, S., O’Donnell, T. J., Krasnowand, M. M., and Glowacki, L. (2019). Universality and diversity in human song. Science, 366, eaax0868. https://doi.org/10.1126/science.aax0868

Mehr, S. A., Singh, M., York, H., Glowacki, L., and Krasnow, M. M. (2018). Form and function in human song. Current Biology, 28, 1-13. https://doi.org/10.1016/i.cub.2017.12.042

Miller, G. F. (2000). Evolution of human music through sexual selection. In N. L. Wallin, B. Merker, and S. Brown (Eds.), The Origins of Music (pp. 329-360). MIT Press.

Miller, P. J. O., Biassoni, N., Samuels, A., and Tyack, P. L. (2000). Whale songs lengthen in response to sonar. Nature, 405(6789), 903. https://doi.org/10.1038/35016148

Miton, H., Wolf, T., Vesper, C., Knoblich, G., and Sperber, D. (2020). Motor constraints influence cultural evolution of rhythm. Proceedings of the Royal Society B: Biological Sciences, 287(1937), 20202001. https://doi.org/10.1098/rspb.2020.2001

Monechi, B., Gravino, P., Servedio, V. D. P., Tria, F., and Loreto, V. (2017). Significance and popularity in music production. Royal Society Open Science, 4(7). https://doi.org/10.1098/rsos.170433

Morita, T., Koda, H., Okanoya, K., and Tachibana, R. O. (2021). Measuring context dependency in birdsong using artificial neural networks. PLOS Computational Biology, 17(12), e1009707. https://doi.org/10.1371/iournal.pcbi.1009707

Moseley, D. L., Derryberry, G. E., Phillips, J. N., Danner, J. E., Danner, R. M., Luther, D. A., and Derryberry, E. P. (2018). Acoustic adaptation to city 
noise through vocal learning by a songbird. Proceedings of the Royal Society B: Biological Sciences, 285(1888).

https://doi.org/10.1098/rspb.2018.1356

Mundy, R. (2014). Evolutionary categories and musical style from Adler to America. Journal of the American Musicological Society, 67(3), 735-768. https://doi.org/10.1525/iams. 2014.67.3.735.I

Muyiwa, J. (2021). Manipur's Tarao language, on the verge of extinction, is being revived through a musician's folk project. Firstpost. https://www.firstpost.com/art-and-culture/manipurs-tarao-language-on-the-verge-of-extinction-is-being-revived-through-a-musicians-folk-pr oject-9501821.html

Nakamura, E., and Kaneko, K. (2019). Statistical evolutionary laws in music styles. Scientific Reports, 9(1). https://doi.org/10.1038/s41598-019-52380-6

Napier, K., and Shamir, L. (2018). Quantitative sentiment analysis of lyrics in popular music. Journal of Popular Music Studies, 30(4), 161-176. https://doi.org/10.1525/ipms.2018.300411

Negro, G., Kovács, B., and Carroll, G. R. (2022). Bustin' out: the evolution of novelty and diversity in recorded music. In G. Cattani, D. Deichmann, and S. Ferriani (Eds.), The Generation, Recognition and Legitimation of Novelty (Vol. 77, pp. 51-87). Emerald Publishing Limited. https://doi.org/10.1108/s0733-558x20220000077007

Nettl, B. (2006). Response to Victor Grauer: on the concept of evolution in the history of ethnomusicology. The World of Music, 48(2), 59-72. https://www.jstor.org/stable/41699696\%0A

Nettl, B. (2015). The Study of Ethnomusicology: Thirty-three Discussions (3rd ed.). University of Illinois Press.

Nettl, B., and Bohlman, P. V. (Eds.). (1991). Comparative Musicology and Anthropology of Music: Essays on the History of Ethnomusicology. University of Chicago Press.

Nia, H. T., Jain, A. D., Liu, Y., Alam, M.-R., Barnas, R., and Makris, N. C. (2015). The evolution of air resonance power efficiency in the violin and its ancestors. Proceedings of the Royal Society of London A, 471, 20140905. https://doi.org/10.1098/rspa.2014.0905

Nikolsky, A., Alekseyev, E., Alekseev, I., and Dyakonova, V. (2020) The overlooked tradition of "personal music" and its place in the evolution of music. Frontiers in Psychology, 10, 3051. https://doi.org/10.3389/fpsyg.2019.03051

Noble, S. U. (2018). Algorithms of Oppression. New York University Press.

Norenzayan, A., Shariff, A. F., Gervais, W. M., Willard, A. K., McNamara, R. A., Slingerland, E., and Henrich, J. (2016). The cultural evolution of prosocial religions. Behavioral and Brain Sciences, 39. https://doi.org/10.1017/S0140525X14001356

O’Dair, M., and Fry, A. (2020). Beyond the black box in music streaming: the impact of recommendation systems upon artists. Popular Communication, 18(1), 65-77. https://doi.org/10.1080/15405702.2019.1627548

Ortega, J. L. (2021). Cover versions as an impact indicator in popular music: A quantitative network analysis. PLOS ONE, 16(4), e0250212. https://doi.org/10.1371/journal.pone.0250212

Ozaki, Y., McBride, J., Benetos, E., Pfordresher, P., Six, J., Tierney, A. T., Proutskova, P., Sakai, E., Kondo, H., Fukatsu, H., Fujii, S., and Savage, P. E. (2021). Agreement among human and automated transcriptions of global songs. Proceedings of the 22nd International Conference on Music Information Retrieval (ISMIR 2021). https://doi.org/10.31234/osfio/isa4u

Patel, A. D. (2008). Music, Language and the Brain. Oxford University Press.

Patel, A. D. (2018). Music as a transformative technology of the mind: An update. In H. Honing (Ed.), The Origins of Musicality (pp. 113-126). Cambridge, MA: MIT Press.

Patel, A. D., and von Rueden, C. (2021). Where they sing solo: Accounting for cross-cultural variation in collective music-making in theories of music evolution. Behavioral and Brain Sciences, 44, E85. https://doi.org/10.1017/S0140525X20001089

Park, D., Bae, A., Schich, M. and Park, J. (2015). Topology and evolution of the network of western classical music compose, EPJ Data Science, 4(2). https://doi.org/10.1140/epjds/s13688-015-0039-z

Parks, S. E., Clark, C. W., and Tyack, P. L. (2007). Short- and long-term changes in right whale calling behavior: The potential effects of noise on acoustic communication. The Journal of the Acoustical Society of America, 122(6), 3725-3731. https://doi.org/10.1121/1.2799904

Passmore, S., Wood, A. L. C., Barbieri, C., Shilton, D., Daikoku, H., Atkinson, Q. D., and Savage, P. E. (in prep). Global relationships between musical, linguistic, and genetic diversity.

Pendlebury, C. (2020). Tune families and tune histories: melodic resemblances in British and Irish folk tunes. Folk Music Journal, 11(5), 67-95.

Percino, G., Klimek, P., Thurner, S. (2014). Instrumentational complexity of music genres and why simplicity sells. PLoS ONE, $9(12)$. https://doi.org/10.1371/journal.pone.0115255

Pinker, S. (1997). How the Mind Works. Norton.

Rahaim, M. (2006). What else do we say when we say “music evolves”? The World of Music, 48(3), 29-41.

Ravignani, A., Delgado, T., and Kirby, S. (2017). Musical evolution in the lab exhibits rhythmic universals. Nature Human Behaviour, 1(1). https://doi.org/10.1038/s41562-016-0007

Ravignani, A., Thompson, B., Grossi, T., Delgado, T., and Kirby, S. (2018). Evolving building blocks of rhythm: How human cognition creates music via cultural transmission. Annals of the New York Academy of Sciences, 1423(1), 176-187. https://doi.org/10.1111/nyas.13610

Risch, D., Corkeron, P. J., Ellison, W. T., and van Parijs, S. M. (2012). Changes in humpback whale song occurrence in response to an acoustic source 200 km away. PLoS ONE, 7(1), 2-7.https://doi.org/10.1371/journal.pone.0029741

Rodriguez Zivic, P. H., Shifres, F., and Cecchi, G. A. (2013). Perceptual basis of evolving western musical styles. Proceedings of the National Academy of Sciences, 110(24), 10034-10038. https://doi.org/10.1073/pnas.1222336110

Roeske, T. C., Kelty-Stephen, D., and Wallot, S. (2018). Multifractal analysis reveals music-like dynamic structure in songbird rhythms. Scientific Reports, 8(1), 1-15. https://doi.org/10.1038/s41598-018-22933-2

Roeske, T. C., Tchernichovski, O., Poeppel, D., and Jacoby, N. (2020). Categorical rhythms are shared between songbirds and humans. Current Biology, 30(18), 3544-3555.e6. https://doi.org/10.1016/i.cub.2020.06.072

Roederer, J. G. (1984). The search for a survival value of music. Music Perception, 1(3), 350-356. https://doi.org/10.2307/40285265

Rohrmeier, M., Zuidema, W., Wiggins, G. A., and Scharff, C. (2015). Principles of structure building in music, language and animal song. Philosophical Transactions of the Royal Society B, 370, 20140097. https://doi.org/10.1098/rstb.2014.0097

Rosati, D. P., Woolhouse, M. H., Bolker, B. M., and Earn, D. J. D. (2021). Modelling song popularity as a contagious process. Proceedings of the Royal Society A, 477(2253), 20210457. https://doi.org/10.1098/rspa.2021.0457

Rothenberg, D., Roeske, T. C., Voss, H. U., Naguib, M., and Tchernichovski, O. (2014). Investigation of musicality in birdsong. Hearing Research, 308, 
71-83. https://doi.org/10.1016/j.heares.2013.08.016

Salganik, M. J., Dodds, P. S., and Watts, D. J. (2006). Experimental study of inequality and unpredictability in an artificial cultural market. Science, 311(5762), 854-856. https://doi.org/10.1126/science.1121066

Salganik, M., and Watts, D. (2008). Leading the herd astray: an experimental study of self-fulfilling prophecies in an artificial cultural market. Social Psychology Quarterly, 71(4), 338-355. https://doi.org/10.1177\%2F019027250807100404

Savage, P. E. (2017). Measuring the Cultural Evolution of Music: With Case Studies of British-American and Japanese Folk, Art, and Popular Music [Doctoral dissertation]. Tokyo University of the Arts. https://tinyurl.com/savagephd

Savage, P. E. (2018). Alan Lomax’s Cantometrics Project: a comprehensive review. Music and Science, 1, 1-19. https://doi.org/10.1177/2059204318786084

Savage, P. E. (2019). Cultural evolution of music. Palgrave Communications, 5(16). https://doi.org/10.1057/s41599-019-0221-1f5z3

Savage, P. E., and Atkinson, Q. D. (2015). Automatic tune family identification by musical sequence alignment. In M. Müller and F. Wiering (Eds.), Proceedings of the 16th International Society for Music Information Retrieval Conference (ISMIR 2015) (pp. 162-168). http://ismir2015.uma.es/articles/76 Paper.pdf

Savage, P. E., and Brown, S. (2013). Toward a new comparative musicology. Analytical Approaches to World Music, 2(2), 148-197. https://doi.org/10.31234/osf.io/a3egp

Savage, P. E., Brown, S., Sakai, E., and Currie, T. E. (2015). Statistical universals reveal the structures and functions of human music. Proceedings of the National Academy of Sciences of the United States of America, 112(29), 8987-8992. https://doi.org/10.1073/pnas.1414495112

Savage, P. E., Cronin, C., Müllensiefen, D., and Atkinson, Q. D. (2018). Quantitative evaluation of music copyright infringement. In A. Holzapfel and A. Pikrakis (Eds.), Proceedings of the 8th International Workshop on Folk Music Analysis (FMA2018) (pp. 61-66). http://fma2018.mus.auth.gr/files/papers/FMA2018 paper 4.pdf

Savage, P. E., Loui, P., Tarr, B., Schachner, A., Glowacki, L., Mithen, S., and Fitch, W. (2021a). Music as a coevolved system for social bonding. Behavioral and Brain Sciences, 44, E59. https://doi.org/10.1017/S0140525X20000333

Savage, P. E., Loui, P., Tarr, B., Schachner, A., Glowacki, L., Mithen, S., and Fitch, W. T. (2021b). Authors' response: Toward inclusive theories of the evolution of musicality. Behavioral and Brain Sciences, 44(e121), 132-140. https://doi.org/10.1017/S0140525X21000042

Savage, P. E., Passmore, S., Chiba, G., Currie, T. E., Suzuki, H., and Atkinson, Q. D. (2022). Sequence alignment of folk song melodies reveals cross-cultural regularities of musical evolution. Current Biology, 32, e1-8. https://doi.org/10.1016/j.cub.2022.01.039

Savage, P. E., Tierney, A. T., and Patel, A. D. (2017). Global music recordings support the motor constraint hypothesis for human and avian song contour. Music Perception, 34(3), 327-334. https://doi.org/10.1525/MP.2017.34.3.327

Schneider, L., and Gros, C. (2019). Five decades of US, UK, German and Dutch music charts show that cultural processes are accelerating. Royal Society Open Science, 6(8). https://doi.org/10.1098/rsos.190944

Scott-Phillips, T., Tominaga, A., and Miton, H. (2021). Ecological and psychological factors in the cultural evolution of music. Behavioral and Brain Sciences, 44(e110), 116-117. https://doi.org/10.1017/S0140525X20001181

Seeger, A. (1992). Ethnomusicology and music law. Ethnomusicology, 36(3), 345-359.

Serra, X. (2017). The computational study of a musical culture through its digital traces. Acta Musicologica, 89(1), 24-44.

Serrà, J., Corral, Á., Boguñá, M., Haro, M., and Arcos, J. L. (2012). Measuring the evolution of contemporary western popular music. Scientific Reports, 2. https://doi.org/10.1038/srep00521

Serrà, J., Gómez, E., and Herrera, P. (2010). Audio cover song identification and similarity: Background, approaches, evaluation, and beyond. In Z. W. Raś and A. A. Wieczorkowska (Eds.), Advances in Music Information Retrieval (Studies in Computational Intelligence, vol.274)(pp. 307-332). Springer. https://doi.org/10.1007/978-3-642-11674-2 14

Serra-Peralta, M., Serrà, J., and Corral, Á. (2021). Heaps' law and vocabulary richness in the history of classical music harmony. EPJ Data Science, 10(40). https://doi.org/10.1140/epids/s13688-021-00293-8

Slabbekoorn, H. (2013). Songs of the city: noise-dependent spectral plasticity in the acoustic phenotype of urban birds. Animal Behaviour, 85(5), 1089-1099. https://doi.org/10.1016/i.anbehav.2013.01.021

Sinclair, N. C., Ursell, J., South, A., and Rendell, L. (2022). From Beethoven to Beyoncé: do changing aesthetic cultures amount to "cumulative cultural evolution?" Frontiers in Psychology, 12(663397), 1-15. https://doi.org/10.3389/fpsyg.2021.663397

Smith, A. (2020). Spotify's "plagiarism detector" aims to expose music that is unoriginal. The Independent. https://www.independent.co.uk/life-style/gadgets-and-tech/spotify-plagiarism-detector-music-b1767298.html

Sterelny, K. (2018). Religion re-explained. Religion, Brain and Behavior, 8(4), 406-425. https://doi.org/10.1080/2153599X.2017.1323779

Strachan, J. W. A., Curioni, A., Constable, M. D., Knoblich, G., and Charbonneau, M. (2021). Evaluating the relative contributions of copying and reconstruction processes in cultural transmission episodes. PLoS ONE, 16(9), e0256901. https://doi.org/10.1371/journal.pone.0256901

Street, S., Eerola, T., and Kendal, J. (2021). The role of population size in folk tune complexity. PsyArXiv. https://doi.org/10.31234/osf.io/2he8k

Strigul, N. (2009). Can imitation explain dialect origins? Ecological Modelling, 220(20), 2624-2639. https://doi.org/10.1016/i.ecolmodel.2009.07.005

Taruskin, R. (2005). The Oxford History of Western Music [5 vols.]. Oxford University Press.

Teitelbaum, T., Balenzuela, P., Cano, P., and Buldú, J. M. (2008). Community structures and role detection in music networks. Chaos, $18(4), 043105$. https://doi.org/10.1063/1.2988285

Tëmkin, I., and Eldredge, N. (2007). Phylogenetics and material cultural evolution. Current Anthropology, 48(1), 146-154. https://doi.org/10.1086/510463

Ternovski, J., and Yasseri, T. (2020). Social complex contagion in music listenership: A natural experiment with 1.3 million participants. Social Networks, 61, 144-152. https://doi.org/10.1016/i.socnet.2019.10.005

Thoret, E., Caramiaux, B., Depalle, P., and McAdams, S. (2021). Learning metrics on spectrotemporal modulations reveals the perception of musical instrument timbre. Nature Human Behaviour, 5, 369-377. https://doi.org/10.1038/s41562-020-00987-5

Tierney, A. T., Russo, F. A., and Patel, A. D. (2011). The motor origins of human and avian song structure. Proceedings of the National Academy of Sciences of the United States of America, 108(37), 15510-15515. https://doi.org/10.1073/pnas.1103882108

Toussaint, G. T. (2002). A mathematical analysis of African, Brazilian, and Cuban clave rhythms. Proceedings of BRIDGES: Mathematical Connections in Art, Music and Science, 157-168.

Toussaint, G. T. (2003). Classification and phylogenetic analysis of African ternary rhythm timelines. Proceedings of BRIDGES: Mathematical Connections 
in Art, Music and Science, 25-36.

Trehub, S. E. (2015). Cross-cultural convergence of musical features. Proceedings of the National Academy of Sciences of the United States of America, 112(29), 8809-8810. https://doi.org/10.1073/pnas.1510724112

van Venrooij, A. (2015). A community ecology of genres: Explaining the emergence of new genres in the UK field of electronic/dance music, 1985-1999. Poetics, 52, 104-123. https://doi.org/10.1016/i.poetic.2015.06.005

Varnum, M. E. W., Krems, J. A., Morris, C., Wormley, A., and Grossmann, I. (2021). Why are song lyrics becoming simpler? A time series analysis of lyrical complexity in six decades of American popular music. PLoS ONE, 16(1), 14-19. https://doi.org/10.1371/journal.pone.0244576

Verhoef, T., and Ravignani, A. (2021). Melodic universals emerge or are sustained through cultural evolution. Frontiers in Psychology, $12,668300$. https://doi.org/10.3389/fpsyg. 2021.668300

Weiß, C., Balke, S., Abeßer, J., and Müller, M. (2018). Computational corpus analysis: A case study on jazz solos. Proceedings of the 19th ISMIR Conference, 416-423. https://archives.ismir.net/ismir2018/paper/000023.pdf

Weiß, C., Mauch, M., Dixon, S. and Müller, M. (2019). Investigating style evolution of western classical music: a computational approach, Musicae Scientiae, 23(4), 486-507, https://doi.org/10.1177/1029864918757595

Werner, A. (2020). Organizing music, organizing gender: algorithmic culture and Spotify recommendations. Popular Communication, 18(1), 78-90. https://doi.org/10.1080/15405702.2020.1715980

Westenberger, S. (2021). Drifting to the top? Disentangling mechanisms influencing the turnover rate of popular music the turnover rate of popular music. The Journal of Mathematical Sociology. https://doi.org/10.1080/0022250X.2021.1956918

Windram, H. F., Charlston, T. and Howe, C.J. (2014). A phylogenetic analysis of Orlando Gibbons's Prelude in G, Early Music, 42(4), 515-528. https://doi.org/10.1093/em/cau100

Wood, A. L. C. (2018). "Like a cry from the heart": an insider's view on the genesis of Alan Lomax's ideas and the legacy of his research: Part II. Ethnomusicology, 62(3), 403-438. https://doi.org/10.5406/ethnomusicology.62.3.0403

Wood, A. L. C., Kirby, K. R., Ember, C. R., Silbert, S., Daikoku, H., McBride, J., Passmore, S., Paulay, F., Flory, M., Szinger, J., D’Arcangelo, G., Guarino, M., Atayeva, M., Rifkin, J., Baron, V., El Hajli, M., Szinger, M., and Savage, P. E. (2021). The Global Jukebox: A public database of performing arts and culture. PsyArXiv. https://doi.org/10.31234/osf.io/4z97i

Youngblood, M. (2019a). Cultural transmission modes of music sampling traditions remain stable despite delocalization in the digital age. PLOS ONE, 14(2), e0211860. https://doi.org/10.1371/iournal.pone.0211860

Youngblood, M. (2019b). Conformity bias in the cultural transmission of music sampling traditions. Royal Society Open Science, 6(9), 191149. https://doi.org/10.1098/rsos.191149

Youngblood, M., Baraghith, K., and Savage, P. E. (2021). Phylogenetic reconstruction of the cultural evolution of electronic music via dynamic community detection (1975-1999). Evolution and Human Behaviour, 42(6), 573-582. https://doi.org/10.1016/i.evolhumbehav.2021.06.002

Youngblood, M., and Lahti, D. (2022). Content bias in the cultural evolution of house finch song. Animal Behaviour, 185, 37-48. https://doi.org/10.1016/ianbehav.2021.12.012

Yuan, Y., Oishi, S., Cronin, C., Müllensiefen, D., Atkinson, Q. D., Fujii, S., and Savage, P. E. (2020). Perceptual vs. automated judgments of music copyright infringement. Proceedings of the 21st International Society for Music Information Retrieval Conference (ISMIR 2020), 23-29. https://doi.org/10.31234/osf.io/tq7v5

Zandberg, L., Lachlan, R. F., Lamoni, L., and Garland, E. C. (2021). Global cultural evolutionary model of humpback whale song. Philosophical Transactions of the Royal Society B, 20200242. https://doi.org/10.1098/rstb.2020.0242 